\title{
Automatic Car Parking System using PLC
}

\author{
Akshat Gandhi ${ }^{1}$ \\ B.TECH Electrical Engineering \\ Indus University, Ahmedabad \\ Gujarat, India.
}

\begin{abstract}
In this project I made a system which will be use in multilevel parking. This system will show the driver exact place to park his/her vehicle at the entry point of parking in the screen outside of the parking. Also it counts the total number of car parking is available and show it to the display outside the parking so it will help the driver to park vehicle. At the entrance he/she will see the spot number which is empty so driver will park his/her car at that particular spot so it saves the time of the driver to find the spot and park the vehicle. This project is based on INDUSTRIAL AUTOMATION TECHNOLOGY.
\end{abstract}

Keywords: Industrial Automation, PLC, HMI, Arduino, Stepper Motor, ULN 2003AN, Ladder Diagram, Parking problems.

\section{INTRODUCTION}

Nowadays every person owns a vehicle, as the number of vehicle increases parking problem increases. The growth rate of personal cars is higher in the populated cities like Delhi, Mumbai, and Bangalore etc. The main parking problems are faced by malls, public parking places, cinemas, commercial buildings, hospitals etc. ${ }^{[1]}$

The problem faced by driver in public parking places are mentioned as below.

Wait for turn at entry point.

$>$ Wasting of time in finding empty parking spot.

$>$ Some of the places give first free hour of parking at free but time wastes in finding parking spot.

$>$ Not easy to count how many cars are currently in the parking.

$>$ Also not easy to count how many empty spots are available.

In this project we are going to make an automation base system which will guide the driver to the direct empty parking spot. This system reduces the time in parking and can count the total number cars available in the parking and total spots available in the parking for car. Also it is easy to install, less maintenance and affordable. Also it will reduce the waiting line of car.

\section{1:2 Concept}

The main purpose of this project is to make parking easy for driver and also for the operator who is handling the parking area. This project also includes the study of plc, hmi, arduino board, sensors etc. instruments which are members of Industrial Automation family. Also it includes the basic learning of wiring in panel box. In this project we made a representation of parking with the capacity of 10 cars at a time with a different entry and exit point.

\author{
Prof. Hinal Shah ${ }^{2}$ \\ Asst. Professor \\ Indus University, Ahmedabad \\ Gujarat, India.
}

\section{DESCRIPTION OF SYSTEM}

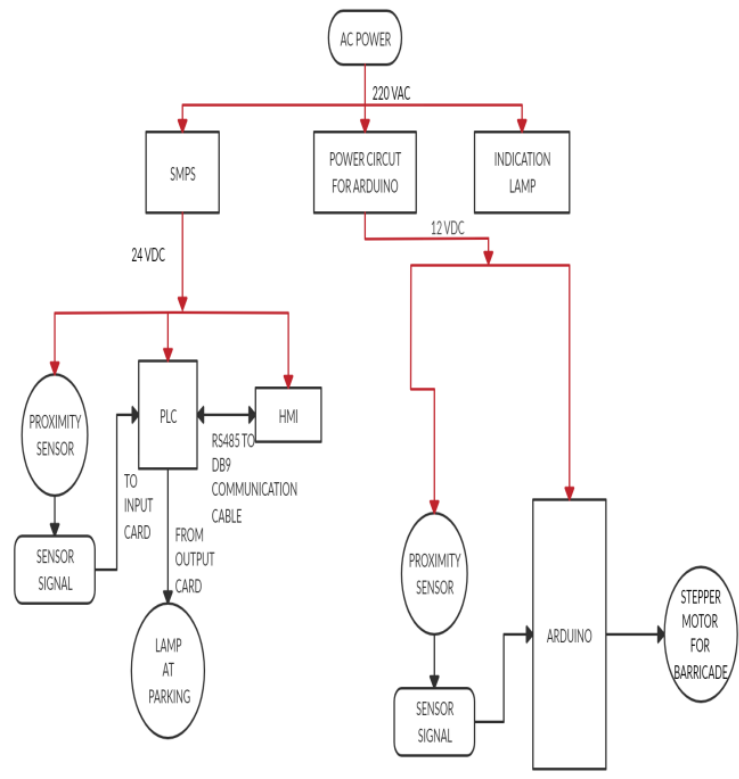

In the above block diagram red line shows power circuit and black line suggest control circuit.

2:1 Hardware Required

1 - PLC: Selec Flexys Rail Type

- Use to keep the record of number of car and to check the condition of parking spot.

- Language: Ladder diagram

- Software: SELPRO Ver. 5.3.7

2 - HMI: ATSEL 7" HMI by selec ${ }^{[2]}$

- Use as a display to show the condition of parking slots outside the entrance of the parking for driver.

- Software: ATSEL by selec

3 - Sensor: PNP NO Proximity Sensor ${ }^{[3]}$

- Use to check the condition of parking slot and give the signal to PLC according to the parking situation.

4 - SMPS

- Use to convert $230 \mathrm{~V}$ AC supply into $24 \mathrm{~V}$ DC supply.

- $\quad$ 24V DC supply required for PLC, HMI, Proximity Sensors and LED indicators.

5 - Arduino Board ${ }^{[4]}$

- Use to control the gate movement at the entry and exit point. 


\section{6 - Stepper Motor ${ }^{[5]}$}

- It is a 5 pin stepper motor. Which is use to move the door up and down according to the car situation.

7 - ULN 2003AN Driver

- It receives the signal from Arduino and gives it to the Stepper motor according to the code uploaded on the board according to application.

8 - Led Lights

- Use to indicate the parking situation i.e. When the LED is on at the parking spot it will indicate that parking spot is empty.

- At the entry and exit gate RED light indicates stop and GREEN light indicates go signal.

\section{2:2 How it works?}

In this project we are using RAIL TYPE PLC. In this type of plc we can add/remove IO card according to the application. The main purpose of PLC is to make a process fast and accurate. Also it is use to keep the record of number of the car available in the parking, also the parking spots which are full and empty.

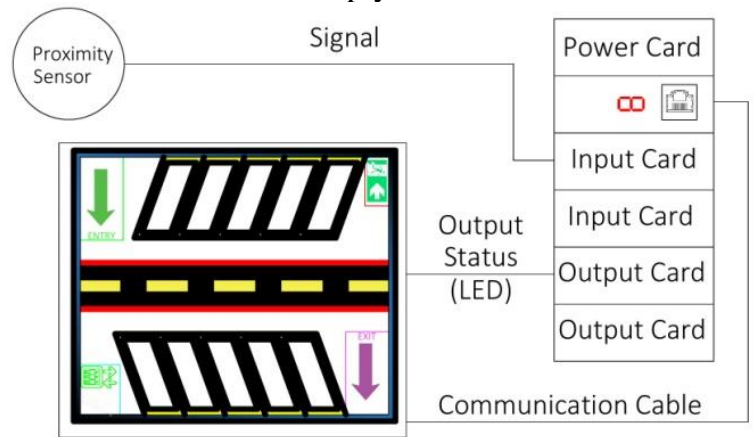

Block Diagram of PLC to HMI

There are proximity sensors connected at each parking spot which will detect the car and give the signal to PLC. After receiving the signal PLC will count the number of car and give the status to HMI which will fixed at the outside of parking which shows the current condition of each slots in the parking. Below is fig. of parking layout.

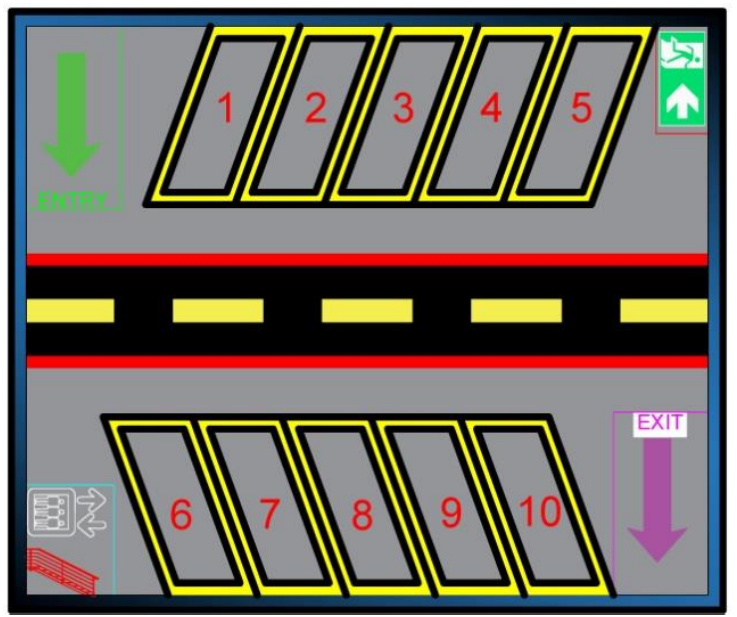

Figure 1 Layout of Parking

\section{2:3 Working of Arduino}

For the movement of gate when the car enters there is a stepper motor connected with arduino uno board through uln2003an driver.

When the car arrives at the entry point there is a proximity sensor which will detect the car. Also there is a LED light which will indicate the current condition (turn on - stop signal and turn off - go inside the parking).

When the car arrives at the entry point light is glowing and it will detect by the sensor (Fig. a). After the detection of car the door will open and light goes off (Fig. b). When the car goes door will open for prescribed time and light remains off (Fig. c). After prescribed time door will be back to its normal position (Fig. d). Light goes on for the next car (Fig. e).

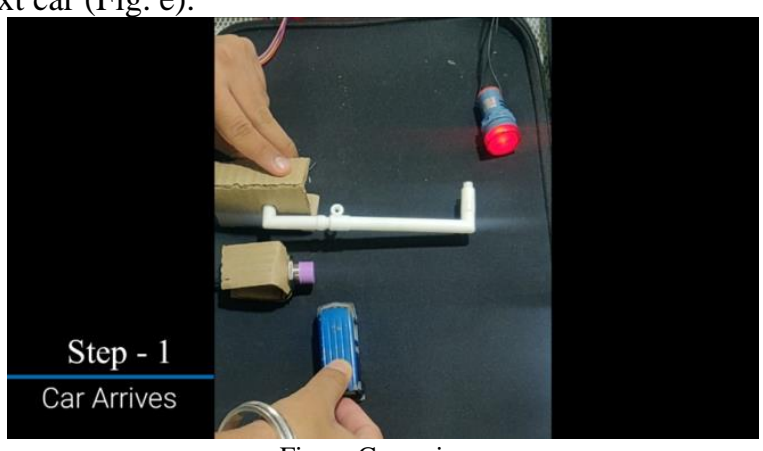

Fig. a: Car arrives

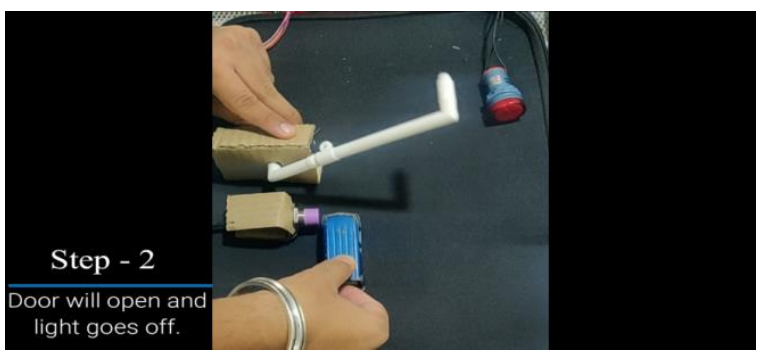

Fig. b: Door open and Light goes off.

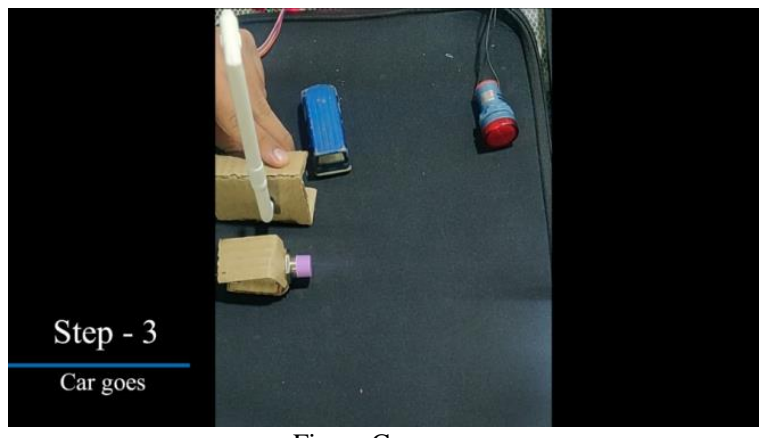

Fig. c: Car goes

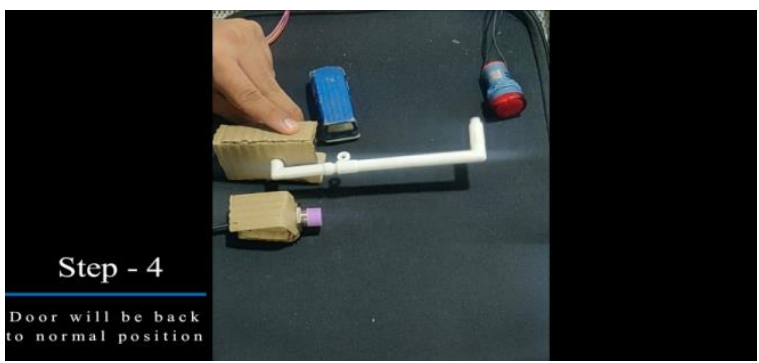

Fig. d: Door will be back to normal position 


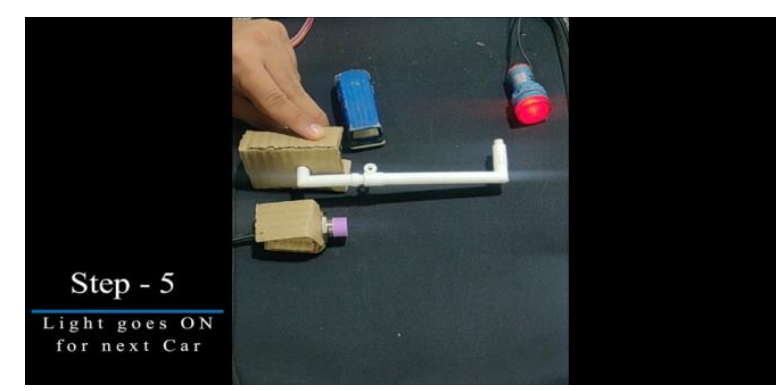

Fig. e: Light on for the next car.

\section{CONCLUSION AND FUTURE SCOPES}

\section{3:1 Conclusion}

- By this project we concluded that we can reduce the waiting line outside the parking also it will save the time of driver during parking and it is easy to record the number of car parked inside the parking.

\section{3:2 Future Scopes}

- RFID tag for personal parking.

- QR code of e-wallet for paid parking.

- Image processing for record of the car.

- Specified parking slot at the entrance.

\section{REFERENCES}

[1] https://www.sciencedirect.com/science/article/pii/S20957564183057 86

[2] https://www.inductiveautomation.com/resources/article/what-is-hmi

[3] https://www.educba.com/what-is-proximity-sensors/

[4] https://components101.com/microcontrollers/arduino-uno

[5] https://components101.com/motors/28byj-48-stepper-motor 